\title{
Work-family conflict as a mediator between occupational stress and psychological health among mental health nurses in Japan
}

This article was published in the following Dove Press journal:

Neuropsychiatric Disease and Treatment

13 March 2017

Number of times this article has been viewed

\author{
Norio Sugawara ${ }^{1,2}$ \\ Kazuma Danjo 3 \\ Hanako Furukori ${ }^{4}$ \\ Yasushi Sato 2,5 \\ Tetsu Tomita ${ }^{2,6}$ \\ Akira Fujii ${ }^{7}$ \\ Taku Nakagami ${ }^{2,8}$ \\ Kazuyo Kitaoka9 \\ Norio Yasui-Furukori ${ }^{2}$ \\ 'Department of Clinical Epidemiology, \\ Translational Medical Center, National \\ Center of Neurology and Psychiatry, \\ Kodaira, Tokyo, ${ }^{2}$ Department of \\ Neuropsychiatry, Hirosaki University \\ School of Medicine, Hirosaki, \\ Aomori, ${ }^{3}$ Mizoguchi Mental Hospital, \\ Shizuoka, ${ }^{4}$ Department of Psychiatry, \\ Kuroishi-Akebono Hospital, \\ Kuroishi, ${ }^{5}$ Department of Psychiatry, \\ Mutsu General Hospital, Mutsu, \\ ${ }^{6}$ Department of Psychiatry, Hirosaki- \\ Aiseikai Hospital, Kitazono, Hirosaki, \\ ${ }^{7}$ Department of Psychiatry, Seihoku- \\ Chuoh Hospital, Goshogawara, \\ Aomori, ${ }^{8}$ Department of Psychiatry, \\ Odate Municipal General Hospital, \\ Odate, Akita, ${ }^{9}$ Mental Health Nursing, \\ Institute of Medical, Pharmaceutical \\ and Health Sciences, Kanazawa \\ University, Kanazawa, Ishikawa, Japan
}

Correspondence: Norio Sugawara Department of Clinical Epidemiology, Translational Medical Center, National Center of Neurology and Psychiatry, Kodaira I87-855I, Tokyo, Japan

Tel +8I 42 34| 27I2

Email nsuga3@yahoo.co.jp
Background: Occupational stress among mental health nurses may affect their psychological health, resulting in reduced performance. To provide high-quality, sustainable nursing care, it is necessary to identify and control the factors associated with psychological health among mental health nurses. The purpose of this study was to examine the role of work-family conflict (WFC) in the well-known relationship between occupational stress and psychological health among mental health nurses in Japan.

Methods: In this cross-sectional study, data were gathered from 180 mental health nurses who had a coresident child or were married. Data from the Work-Family Conflict Scale, the Generic Job Stress Questionnaire, the Maslach Burnout Inventory-General Survey, and the Center for Epidemiologic Studies for Depression Scale were obtained via self-report questionnaires. The effects of occupational stress and WFC on psychological health were explored by hierarchical linear regression analysis.

Results: The relationship between emotional exhaustion and occupational factors, including quantitative workload and the variance in workload, disappeared with the addition of WFC (each work interference with family [WIF] or family interference with work [FIW]). The relationship between emotional exhaustion and mental demands disappeared only with the addition of WIF. The relationship between depressive symptoms and variance in workload disappeared with the addition of WFC (each WIF or FIW).

Conclusion: Our findings may encourage hospital administrators to consider the risks of medical staff WFC. Furthermore, longitudinal investigations into the factors associated with WFC are required for administrative and psychological interventions.

Keywords: burnout, depression, occupational stress, work-family conflict

\section{Introduction}

Mental health nurses frequently encounter such multidimensional stressors as demanding or difficult patients, ${ }^{1}$ inadequate staffing, ${ }^{2}$ physically threatening patients, and potential suicides. ${ }^{3,4}$ Mental health nursing has been recognized as a highly stressful occupation, and previous studies have demonstrated the relationship between occupational stressors and psychological health, resulting in depression or burnout. ${ }^{5,6}$ To provide high-quality, sustainable nursing care, it is necessary to identify and control the factors associated with psychological health among mental health nurses.

Recently, in addition to the established work stress measures, work-family conflict (WFC) has been recognized as an important factor in organizational behavior and occupational health. WFC has been defined as "a form of inter-role conflict in which the role pressures from the work and family domains are mutually incompatible in 
some respects." ${ }^{\text {7 }}$ Participation in one role makes it difficult to participate in the other. This definition of WFC implies bidirectional relationships between work and family life, and previous factor analysis studies identified two types of WFC: work interference with family (WIF) conflict and family interference with work (FIW) conflict. ${ }^{8}$ Theoretically, the definition of WFC implies mediation; WFC can mediate the way we experience demands over a prolonged period of time. ${ }^{9}$

Several studies have shown that WFC is associated with a wide range of occupational, family, and psychological outcomes. ${ }^{10-13}$ Medical staff who devote a large amount of time and energy to their work, ${ }^{14,15}$ may experience higher WFC. ${ }^{16}$ More than half of Japanese family households consist of the nuclear family, that is, the father, mother, and child. ${ }^{17}$ Compared to extended families, nuclear families might be more sensitive to stressful events. ${ }^{18}$ However, there has been limited evidence of WFC among medical staff in Japan. Thus, research is required to evaluate the relationship between WFC, occupational stress, and psychological health among Japanese mental health nurses.

The objective of the current investigation was to examine the role of WFC in the association between occupational stress and psychological health among mental health nurses who had a coresident child or were married in Japan. To our knowledge, this study is the first to examine WFC in Japanese mental health nurses.

\section{Materials and methods Participants}

This study was conducted between September and November 2012. Self-report questionnaire packages were mailed to 7 randomly selected hospitals that are affiliated with Hirosaki University School of Medicine, and the surveys were then distributed to 318 nurses. Three of the hospitals were psychiatric hospitals, and 4 of the hospitals were general hospitals. All respondents provided their verbal informed consent to participate in this study, and no incentives were offered for participation. The anonymous questionnaire was the only research instrument, and the following statement was included: "completion of the attached questionnaire will be considered your consent to participate." In total, 20 or 30 minutes were needed to answer the questionnaires. Before the questionnaires were distributed, nurses were well informed about the study and the potential risks and benefits of their participation by the research team. Questionnaires were distributed to nurses who showed willingness to participate in the study. Subsequently, nurses had the right to not submit the questionnaires if they wished to withdraw from the study.
To avoid common method variance, the participants were allowed to answer the questionnaire at places of their choosing. Of the 318 distributed surveys, responses were received from 240 nurses, and 238 questionnaires (response rate $74.8 \%$ ) were completed. The questionnaires were collected by collaborators in a sealed envelope. The characteristics of the study population have been reported previously. ${ }^{5}$ In this study, we reanalyzed the 180 mental health nurses who had a coresident child or were married from the same study population. The study protocol was approved by the Ethics Committee of the Hirosaki University School of Medicine (2012-2013). All of the respondents participated in the study without any incentive.

\section{Assessment of WFC}

We used the 18 items of the Japanese version of the WorkFamily Conflict Scale in this study. ${ }^{19,20}$ This scale covers two types and three dimensions of conflicts, namely, time-based, strain-based, and behavior-based WIF and time-based, strainbased, and behavior-based FIW. Responses were provided on a 5-point Likert scale ranging from 1= "strongly disagree" to $5=$ "strongly agree." Higher scores indicate greater WFC. In this study, we employed two subscales: the WIF scale and the FIW scale. The two scales included 18 items, and each of the two subscales included nine items. The WIF scale measured the extent to which work demands interfere with family-related obligations, whereas the FIW scale measured the extent to which family demands interfere with workrelated obligations.

\section{Assessment of occupational factors}

Job-related stress was assessed with the Generic Job Stress Questionnaire (GJSQ), ${ }^{21}$ which was developed by the National Institute for Occupational Safety and Health. The Japanese version of the GJSQ has demonstrated sufficient reliability and validity. ${ }^{22}$ The original authors of the GJSQ permit the use of their independent subscales for assessing occupational stress, ${ }^{21}$ and we focused on 3 subscales to assess occupational stress: quantitative workload, variance in workload, and mental demands.

\section{Assessment of burnout}

Burnout was assessed using the Japanese version of the Maslach Burnout Inventory-General Survey (MBI-GS). ${ }^{23,24}$ This questionnaire consisted of three subscales: exhaustion (five items), cynicism (five items), and professional efficacy (six items). For each item, respondents used a 7-point Likerttype scale ranging from 0 (never) to 6 (every day). Higher 
scores on the emotional exhaustion and cynicism dimensions and lower scores on the professional efficacy dimension indicated higher levels of burnout.

\section{Assessment of depressive symptoms}

The Japanese version of the Center for Epidemiologic Studies for Depression Scale (CES-D) was administered to all of the participants to measure their depressive status. ${ }^{25,26}$ This questionnaire has been widely used to measure depressive symptoms in community populations and to screen individuals for probable depression. The CES-D is a 20 -item self-report instrument that focuses on depressive symptoms during the week prior to the administration of the questionnaire. The maximum score on this scale is 60 , and higher scores are associated with depression.

\section{Statistical analysis}

The data are presented as the mean \pm standard deviation. A value of $P<0.05$ was considered to be statistically significant. To compare the characteristics between genders, the unpaired Student's $t$-test was performed to analyze continuous variables, and the chi-square test was performed to analyze categorical variables. Pearson's correlation was used to explore the relationships between the psychological and occupational variables. To assess 1) occupational stress once demographic characteristics were controlled and 2) WFC (each the two directions of WIF and FIW conflicts) after demographic characteristics and occupational stress were controlled, we performed hierarchical linear regression analysis for psychological variables (depression and each of the three dimensions of burnout). In step 1 of the hierarchical linear regression analysis, the control variables, namely, age and gender were used as predictors. In step 2, occupational factors (quantitative workload, variance in workload, and mental demands) were added. In step 3, WIF or FIW was added. WIF and FIW were added individually to models $3 \mathrm{a}$ and $3 \mathrm{~b}$. According to Baron and Kenny, ${ }^{27}$ the following conditions should be satisfied to establish mediation: 1) the independent variable (occupational factors) is significantly associated with the dependent variable (depression and each of the three dimensions of burnout); 2) the independent variable is significantly associated with the mediator (WIF/ FIW); and 3) the mediator is significantly associated with the dependent variable, and the effect of the independent variable on the dependent variable decreases with the addition of the mediator to the model. If the independent variable does not affect the dependent variable when the mediator is added to the model, full mediation is established. We assessed multicollinearity using the variance inflation factor (VIF), and all independent variables in our linear regression models showed VIFs $<5$. The data were analyzed using PASW Statistics PC software for Windows, Version 18.0.0 (SPSS Inc., Chicago, IL, USA).

\section{Results}

Table 1 contains the sociodemographic and occupational characteristics of the participants. According to the optimal CES-D cutoff point of 19 that was determined by Wada et al to identify possible cases of depression among working individuals ${ }^{28}$ the frequency of probable depression in the current sample was $34.1 \%$ for males $(\mathrm{n}=14)$ and $34.5 \%$ for females ( $\mathrm{n}=48 ; P>0.05)$. Table 2 indicates Pearson correlations among psychological and occupational variables in mental health nurses.

Table 3 shows the results of the hierarchical linear regression analysis used to assess the effects of occupational factors

Table I Characteristics of participants

\begin{tabular}{|c|c|c|c|c|}
\hline Variables & Total $(n=\mid 80)$ & Male $(n=4 I)$ & Female $(n=139)$ & $P$-value \\
\hline Age & $48.6 \pm 11.5$ & $42.7 \pm 10.6$ & $50.4 \pm 11.2$ & $<0.001$ \\
\hline Married & $84.4 \%(152 / 180)$ & $95.1 \%(39 / 4 I)$ & $81.3 \%(113 / 139)$ & 0.032 \\
\hline Having a coresident child & $76.1 \%(137 / 180)$ & $78.0 \%(32 / 4 I)$ & $75.5 \%(105 / 139)$ & $0.74 I$ \\
\hline Work interference with family & $23.4 \pm 8.1$ & $23.2 \pm 8.5$ & $23.9 \pm 6.9$ & 0.606 \\
\hline Family interference with work & $18.7 \pm 6.2$ & $19.8 \pm 5.6$ & $18.4 \pm 6.4$ & 0.202 \\
\hline \multicolumn{5}{|l|}{ Occupational stress } \\
\hline Quantitative workload & $11.9 \pm 4.0$ & $12.5 \pm 3.7$ & $1 \mathrm{I} .7 \pm 4.1$ & 0.235 \\
\hline Variance in workload & $8.4 \pm 3.3$ & $8.9 \pm 3.2$ & $8.2 \pm 3.3$ & 0.214 \\
\hline Mental demands & $14.9 \pm 2.7$ & $14.3 \pm 3.0$ & $|5| \pm 2.7$. & 0.127 \\
\hline Emotional exhaustion & $14.0 \pm 8.0$ & $13.3 \pm 8.1$ & $14.2 \pm 8.0$ & 0.535 \\
\hline Cynicism & $10.1 \pm 7.3$ & $10.7 \pm 7.3$ & $9.9 \pm 7.3$ & 0.571 \\
\hline Professional efficacy & $11.6 \pm 6.1$ & $12.3 \pm 6.1$ & $11.4 \pm 6.1$ & 0.421 \\
\hline CES-D score & $16.7 \pm 10.5$ & $15.7 \pm 10.5$ & $17.0 \pm 10.6$ & 0.485 \\
\hline
\end{tabular}

Abbreviation: CES-D, Center for Epidemiologic Studies for Depression Scale. 
Table 2 Pearson correlations between psychological and occupational variables

\begin{tabular}{|c|c|c|c|c|c|c|c|c|c|}
\hline Variables & ( 1 ) & $(2)$ & (3) & $(4)$ & (5) & (6) & (7) & (8) & Cronbach's $\alpha$ \\
\hline Work interference with family $(I)$ & & & & & & & & & 0.892 \\
\hline Family interference with work (2) & $0.699 * * *$ & & & & & & & & 0.829 \\
\hline Quantitative workload (3) & $0.508 * * *$ & $0.288 * * *$ & & & & & & & 0.864 \\
\hline Variance in workload (4) & $0.477^{* * *}$ & $0.28 I^{* * *}$ & $0.825 * * *$ & & & & & & 0.913 \\
\hline Mental demands (5) & $0.345^{* * *}$ & 0.089 & $0.450 * * *$ & $0.423 * * *$ & & & & & 0.761 \\
\hline Emotional exhaustion (6) & $0.707^{* * *}$ & $0.503^{* * *}$ & $0.524 * * *$ & $0.517 * * *$ & $0.372 * * *$ & & & & 0.940 \\
\hline Cynicism (7) & $0.585 * * *$ & $0.501 * * *$ & $0.307 * * *$ & $0.359 * * *$ & $0.159 *$ & $0.695^{* * *}$ & & & 0.898 \\
\hline Professional efficacy (8) & -0.065 & -0.022 & -0.026 & 0.066 & -0.022 & 0.006 & -0.099 & & 0.812 \\
\hline CES-D score (9) & $0.497 * * *$ & $0.446 * * *$ & $0.377 * * *$ & $0.392 * * *$ & $0.167^{*}$ & $0.586 * * *$ & $0.548 * * *$ & $-0.212^{* *}$ & 0.901 \\
\hline
\end{tabular}

Notes: $* P<0.05 ; * * P<0.01 ; * * * P<0.001$.

Abbreviation: CES-D, Center for Epidemiologic Studies for Depression Scale.

and WFC on burnout. The relationship between emotional exhaustion and occupational factors, including quantitative workload and the variance in workload disappeared with the addition of WFC (each WIF or FIW). The relationship between emotional exhaustion and mental demands disappeared only with the addition of WIF. Table 4 presents the results of the hierarchical linear regression analysis used to assess the effects of occupational factors and WFC on depressive symptoms. The relationship between depressive symptoms and variance in workload disappeared with the addition of WFC (each WIF or FIW).

\section{Discussion}

This study identified significant associations between occupational stress and psychological health among Japanese mental health nurses in the model, which did not include WFC factors. Our results were consistent with those of an earlier investigation in which hours of overtime work and job control, assessed by the Brief Job Stress Questionnaire, were correlated with depressive symptoms in a cross-sectional study of 706 female general nurses in Japan. ${ }^{29}$ In a study of 141 Taiwanese female mental health nurses, Lin et al identified a significant interaction between social support and job stress using a multiple linear regression model, which suggested that the ascending trend of depression with elevated job stress, as assessed by the Taiwanese Nurse Stress Checklist, was accelerated in subjects who had a low level of social support. ${ }^{30}$ Among 877 Finnish nurses, there was a linear trend toward increasing workload with increasing absenteeism because of sickness. ${ }^{31}$ Occupational factors and psychological health may affect both job outcomes and quality of care. ${ }^{32}$

Our findings demonstrated the mediating role of WFC in the effect of occupational stress on depression, emotional exhaustion, and cynicism. Although several studies have primarily focused on the direct effect of WFC on both burnout $^{9,33}$ and depression, ${ }^{10,13,34}$ other studies have investigated the mediating effect of WFC on psychological health. Among Greek doctors, Montgomery et al showed that work-family interference partially mediated the relationship between emotional job demands and depersonalization. ${ }^{35} \mathrm{In}$ a German leben in der Albeit (lidA) study $(\mathrm{n}=5,906),{ }^{36}$ crosssectional evidence for the mediating effect of WFC in the association between occupational stress and depression among full- and part-time employed, middle-aged females and males

Table 3 Effects of demographic characteristics, work-related factors, and work-family conflict on burnout

\begin{tabular}{|c|c|c|c|c|c|c|c|c|c|c|c|c|}
\hline \multirow[t]{2}{*}{ Variables } & \multicolumn{4}{|c|}{ Emotional exhaustion } & \multicolumn{4}{|c|}{ Cynicism } & \multicolumn{4}{|c|}{ Professional efficacy } \\
\hline & $\begin{array}{l}\text { Model } \\
\text { I }\end{array}$ & $\begin{array}{l}\text { Model } \\
2\end{array}$ & $\begin{array}{l}\text { Model } \\
3 a\end{array}$ & $\begin{array}{l}\text { Model } \\
\text { 3b }\end{array}$ & $\begin{array}{l}\text { Model } \\
\text { I }\end{array}$ & $\begin{array}{l}\text { Model } \\
2\end{array}$ & $\begin{array}{l}\text { Model } \\
3 a\end{array}$ & $\begin{array}{l}\text { Model } \\
\text { 3b }\end{array}$ & $\begin{array}{l}\text { Model } \\
\text { I }\end{array}$ & $\begin{array}{l}\text { Model } \\
2\end{array}$ & $\begin{array}{l}\text { Model } \\
3 a\end{array}$ & $\begin{array}{l}\text { Model } \\
\text { 3b }\end{array}$ \\
\hline Age, years & -0.14 & -0.12 & -0.04 & -0.07 & $-0.25 * *$ & $-0.22 * *$ & $-0.14 *$ & $-0.17 * *$ & 0.09 & 0.11 & 0.10 & 0.11 \\
\hline Gender & -0.09 & -0.11 & -0.09 & $-0.12 *$ & -0.03 & -0.04 & -0.03 & -0.06 & 0.09 & 0.08 & 0.08 & 0.08 \\
\hline Quantitative workload & & $0.27^{*}$ & 0.09 & 0.19 & & 0.03 & -0.14 & -0.05 & & -0.25 & -0.22 & -0.24 \\
\hline Variance in workload & & $0.22 *$ & 0.15 & 0.18 & & $0.29 *$ & $0.22 *$ & $0.24 *$ & & $0.30 *$ & $0.30 *$ & 0.30 \\
\hline Mental demands & & $0.16^{*}$ & 0.07 & $0.17^{* *}$ & & 0.05 & -0.04 & 0.06 & & -0.04 & -0.03 & -0.05 \\
\hline Work interference with family & & & $0.57 * * *$ & & & & $0.55^{* * *}$ & & & & -0.07 & \\
\hline Family interference with work & & & & $0.38 * * *$ & & & & $0.42^{* * *}$ & & & & -0.02 \\
\hline $\mathrm{n}$ & 180 & 180 & 180 & 180 & 180 & 180 & 180 & 180 & 180 & 180 & 180 & 180 \\
\hline$R^{2}$ & 0.02 & 0.33 & 0.56 & 0.46 & 0.06 & 0.17 & 0.38 & 0.33 & 0.01 & 0.04 & 0.04 & 0.04 \\
\hline
\end{tabular}

Notes: Values are standardized regression coefficients. $* P<0.05 ; * * P<0.01 ; * * * P<0.001$. 
Table 4 Effects of demographic characteristics, work-related factors, and work-family conflict on depressive symptoms

\begin{tabular}{lllll}
\hline Variables & \multicolumn{2}{l}{ Depression } \\
\cline { 2 - 5 } & Model & Model & Model & Model \\
& $\mathbf{I}$ & $\mathbf{2}$ & $\mathbf{3 a}$ & $\mathbf{3 b}$ \\
\hline Age, years & -0.14 & -0.10 & -0.04 & -0.05 \\
Gender & -0.09 & -0.12 & $-0.1 \mathrm{I}$ & -0.13 \\
Quantitative workload & & 0.19 & 0.06 & 0.12 \\
Variance in workload & & $0.25^{*}$ & 0.19 & 0.20 \\
Mental demands & & -0.02 & -0.09 & -0.01 \\
Work interference with family & & & $0.40 * * *$ & \\
Family interference with work & & & & $0.36 * * *$ \\
$\mathrm{n}$ & 180 & 180 & 180 & 180 \\
$R^{2}$ & 0.02 & 0.18 & 0.29 & 0.30 \\
\hline
\end{tabular}

Notes: Values are standardized regression coefficients. $* P<0.05 ; * * * P<0.00$ I.

in full-time positions was obtained. Furthermore, Vignoli et al observed that job demands affected absenteeism by the subsequent mediation of WFC and emotional exhaustion in 245 Italian workers. ${ }^{37}$ These findings should encourage hospital administrators to maintain awareness of WFC. To promote the psychological health of medical staff, efforts should be made to develop strategies to decrease both WIF and FIW. To reduce WIF, hospital administrators could increase staff to reduce quantitative workload and provide opportunities to enhance skills to keep up with progress in medical technology. In addition, hospitals could provide childcare services for childrearing female workers or arrange schedules to allow parents to work flexible hours. By reducing FIW, hospital administrators may prevent the detrimental effect of spillover.

In contrast to our expectations, we did not identify a relationship between WFC and professional efficacy. Previous studies showed that professional efficacy is positively associated with WIF and negatively associated with FIW. One possible explanation is the differences in the mean age of the participants. WFC among individuals with preschoolaged children may be different from WFC among parents with older children. Another explanation is that the nature of professional efficacy, which is different from the other two dimensions of the MBI-GS, may reflect a personal characteristic rather than a genuine burnout component. ${ }^{38}$

\section{Limitations}

Our study has several limitations. First, we simultaneously measured WFC, occupational factors, and psychological variables. The cross-sectional nature of this study did not allow causal assumptions; thus, our results should be confirmed by a longitudinal study. Second, our data were obtained by self-report questionnaires, which could cause reporting bias. Personality factors, response styles, and social desirability may have affected our results. Third, some important occupational factors, such as irregular work schedules, overtime work, personal income, shift work, and working position, were not included in this analysis. Fourth, selection bias may exist because the characteristics of the excluded subjects may differ from those of the study participants. Fifth, our sample was limited to only the Hirosaki University School of Medicine and its affiliated hospitals, which could limit the generalizability of our results.

\section{Conclusion}

Our study revealed that occupational stress affected psychological health and that WFC was a mediator in this relationship in Japanese mental health nurses. Our results have important implications for the management of WFC by administrators in hospitals. In addition, the promotion of an adequate work-life balance among nurses may aid in the prevention of depression. However, the interpretation of our results was hampered by the lack of data on personal income, working hours, and organizational commitment. Furthermore, longitudinal investigation of the factors associated with WFC may yield practical information that is useful for administrative and psychological interventions.

\section{Acknowledgments}

The authors thank all of their colleagues in this study for their skillful contributions to the collection and management of the data. Funding for this study was provided by the Hirosaki Research Institute for the neurosciences; the Hirosaki Research Institute for the neurosciences had no further role in study design; in the collection, analysis and interpretation of data; in the writing of the report; and in the decision to submit the paper for publication.

\section{Disclosure}

The authors report no conflict of interest in this work.

\section{References}

1. Inoue M, Tsukano K, Muraoka M, Kaneko F, Okamura H. Psychological impact of verbal abuse and violence by patients on nurses working in psychiatric departments. Psychiatry Clin Neurosci. 2006;60(1):29-36.

2. Jenkins R, Elliott P. Stressors, burnout and social support: nurses in acute mental health settings. J Adv Nurs. 2004;48(6):622-631.

3. Kishi Y, Kurosawa H, Morimura H, Hatta K, Thurber S. Attitudes of Japanese nursing personnel toward patients who have attempted suicide. Gen Hosp Psychiatry. 2011;33(4):393-397.

4. Takahashi C, Chida F, Nakamura H, et al. The impact of inpatient suicide on psychiatric nurses and their need for support. BMC Psychiatry. 2011;11:38

5. Yoshizawa K, Sugawara N, Yasui-Furukori N, et al. Relationship between occupational stress and depression among psychiatric nurses in Japan. Arch Environ Occup Health. 2016;71(1):10-15. 
6. Melchior ME, Bours GJ, Schmitz P, Wittich Y. Burnout in psychiatric nursing: a meta-analysis of related variables. $J$ Psychiatr Ment Health Nurs. 1997:4(3):193-201.

7. Greenhaus JH, Beutell NJ. Source of conflict between work and family roles. Acad Manage Rev. 1985;10(1):76-88.

8. Netemeyer RG, Boles JS, McMurrian R. Development and validation of work-family conflict and family-work conflict scales. J Appl Psychol. 1996;81(4):400-410.

9. Wang Y, Liu L, Wang J, Wang L. Work-family conflict and burnout among Chinese doctors: the mediating role of psychological capital. J Occup Health. 2012;54(3):232-240.

10. Frone MR, Russell M, Barnes GM. Work-family conflict, gender, and health-related outcomes: a study of employed parents in two community samples. J Occup Health Psychol. 1996;1(1):57-69.

11. Allen TD, Herst DE, Bruck CS, Sutton M. Consequences associated with work-to-family conflict: a review and agenda for future research. J Occup Health Psychol. 2000;5(2):278-308.

12. Jansen NW, Kant I, Kristensen TS, Nijhuis FJ. Antecedents and consequences of work-family conflict: a prospective cohort study. J Occup Environ Med. 2003;45(5):479-491.

13. van Hooff ML, Geurts SA, Taris TW, et al. Disentangling the causal relationships between work-home interference and employee health. Scand J Work Environ Health. 2005;31(1):15-29.

14. Kudo Y, Yoshimura E, Shahzad MT, Shibuya A, Aizawa Y. Japanese professional nurses spend unnecessarily long time doing nursing assistants' tasks. Tohoku J Exp Med. 2012;228(1):59-67.

15. Saijo Y, Chiba S, Yoshioka E, et al. Effects of work burden, job strain and support on depressive symptoms and burnout among Japanese physicians. Int J Occup Med Environ Health. 2014;27(6):980-992.

16. McNamara TK, Pitt-Catsouphes M, Matz-Costa C, Brown M, Valcour M. Across the continuum of satisfaction with work-family balance: work hours, flexibility-fit, and work-family culture. Soc Sci Res. 2013;42(2): 283-298.

17. Ministry of Health, Labor and Welfare, Japan; 2016. Comprehensive survey of living condition. Available from: http://www.mhlw.go.jp/ toukei/saikin/hw/k-tyosa/k-tyosa15/>. Accessed December 18, 2016. Japanese.

18. Abel KM, Heuvelman HP, Jörgensen L, et al. Severe bereavement stress during the prenatal and childhood periods and risk of psychosis in later life: population based cohort study. BMJ. 2014;348:f7679.

19. Watai I, Nishikido N, Murashima S. [Development of a Japanese Version of the Work-Family Conflict Scale (WFCS), and examination of its validity and reliability]. Sangyo Eiseigaku Zasshi. 2006;48(3):71-81. Japanese.

20. Carlson D, Kacmar KM, Williams LJ. Construction and initial validation of a multidimensional measure of work-family conflict. J Vocat Behav. 2000;56(2):249-276.

21. Hurrell JJ Jr, McLaney MA. Exposure to job stress-a new psychometric instrument. Scand J Work Environ Health. 1988;14(Suppl 1):27-28.

22. Haratani T, Kawakami N, Araki S. [Relability and validity of the Japanese version of NIOSH Generic Job Stress Questionnaire]. Jpn J Ind Health. 1993;35:S214. Japanese.
23. Kitaoka-Higashiguchi K, Nakagawa $\mathrm{H}$, Morikawa Y. Construct validity of the Maslach Burnout Inventory-General Survey. Stress Health. 2004; 20:255-260.

24. Maslach C, Jackson SE, Leiter MP. Maslach Burnout Inventory Manual. 3rd ed. Menlo Park, CA: Mind Garden; 1996.

25. Shima S, Shikano T, Kitamura T. [New self-rating scales for depression]. Clin Psychiatry. 1985;27:717-723. Japanese.

26. Radloff LS. The CES-D scale: a self-report depression scale for research in the general population. Appl Psychol Meas. 1977;1:385-401.

27. Baron RM, Kenny DA. The mediator-moderator variable distinction in social psychological research: conceptual, strategic, and statistical considerations. J Pers Soc Psychol. 1986;51(6):1173-1182.

28. Wada K, Tanaka, K, Theriault, G, et al. Validity of the center for epidemiologic studies depression scale as a screening instrument of major depressive disorder among Japanese workers. Am J Ind Med. 2007; 50(1):8-12.

29. Kikuchi Y, Nakaya M, Ikeda M, Okuzumi S, Takeda M, Nishi M. Relationship between job stress, temperament and depressive symptoms in female nurses. Int J Occup Med Environ Health. 2014;27(3): 426-434.

30. Lin HS, Probst JC, Hsu YC. Depression among female psychiatric nurses in southern Taiwan: main and moderating effects of job stress, coping behaviour and social support. J Clin Nurs. 2010;19(15-16): 2342-2354.

31. Rauhala A, Kivimäki M, Fagerström L, et al. What degree of work overload is likely to cause increased sickness absenteeism among nurses? Evidence from the RAFAELA patient classification system. J Adv Nurs. 2007;57(3):286-295.

32. Van Bogaert P, Clarke S, Willems R, Mondelaers M. Nurse practice environment, workload, burnout, job outcomes, and quality of care in psychiatric hospitals: a structural equation model approach. $J A d v$ Nurs. 2013;69(7):1515-1524.

33. Wang Y, Chang Y, Fu J, Wang L. Work-family conflict and burnout among Chinese female nurses: the mediating effect of psychological capital. BMC Public Health. 2012;12:915.

34. Kan D, Yu X. Occupational stress, work-family conflict and depressive symptoms among Chinese bank employees: the role of psychological capital. Int J Environ Res Public Health. 2016;13(1). pii:E134.

35. Montgomery AJ, Panagopolou E, Benos A. Work-family interference as a mediator between job demands and job burnout among doctors. Stress Health. 2006;22(3):203-212.

36. du Prel JB, Peter R. Work-family conflict as a mediator in the association between work stress and depressive symptoms: cross-sectional evidence from the German lidA-cohort study. Int Arch Occup Environ Health. 2015;88(3):359-368.

37. Vignoli M, Guglielmi D, Bonfiglioli R, Violante FS. How job demands affect absenteeism? The mediating role of work-family conflict and exhaustion. Int Arch Occup Environ Health. 2016;89(1):23-31.

38. Hudek-Knezević J, Kalebić Maglica B, Krapić N. Personality, organizational stress, and attitudes toward work as prospective predictors of professional burnout in hospital nurses. Croat Med J. 2011; 52(4):538-549.
Neuropsychiatric Disease and Treatment

\section{Publish your work in this journal}

Neuropsychiatric Disease and Treatment is an international, peerreviewed journal of clinical therapeutics and pharmacology focusing on concise rapid reporting of clinical or pre-clinical studies on a range of neuropsychiatric and neurological disorders. This journal is indexed on PubMed Central, the 'PsycINFO' database and CAS,

\section{Dovepress}

and is the official journal of The International Neuropsychiatric Association (INA). The manuscript management system is completely online and includes a very quick and fair peer-review system, which is all easy to use. Visit http://www.dovepress.com/testimonials.php to read real quotes from published authors. 